\title{
VEGF Expression in Colorectal Cancer Metastatic Lymph Nodes: Clinicopathological Correlation and Prognostic Significance
}

\author{
Inês Mazeda ${ }^{1}$, Sandra F. Martins ${ }^{1,2,3, * \mathbb{C}}$, Eduardo A. Garcia ${ }^{4}$, Mesquita Rodrigues ${ }^{1}$ \\ and Adhemar Longatto $1,2,4,5$ \\ 1 Life and Health Sciences Research Institute (ICVS), School of Medicine, University of Minho, \\ Braga 4710-057, Portugal; ines.mazeda@hotmail.com (I.M.); mesquita.rodrigues@sapo.pt (M.R.); \\ longatto@med.uminho.pt (A.L.) \\ 2 ICVS/3B's—PT Government Associate Laboratory, Braga/Guimarães 4710-057, Portugal \\ 3 Coloproctology Unit, Hospital de Braga, Braga 4710-243, Portugal \\ 4 Molecular Oncology Research Center, Barretos Cancer Hospital, Barretos, São Paulo 14784-400, Brazil; \\ eduardoag@gmail.com \\ 5 Laboratory of Medical Investigation (LIM) 14, Faculty of Medicine, University of São Paulo, \\ São Paulo 1246-903, Brazil \\ * Correspondence: sandramartins@med.uminho.pt; Tel.: +351-253-604827; Fax: +351-253-604847
}

Received: 14 June 2020; Accepted: 26 July 2020; Published: 29 August 2020

\begin{abstract}
Background: Angiogenesis plays an important role in colorectal cancer (CRC) tumorigenesis and metastatic progression. Methods: The present series consisted of CRC lymph node metastasis (LNM) tissue samples from 210 patients. Archival paraffin embedded LNM tissue were used to build up tissue microarray blocks and VEGF expression was immunohistochemically assessed. Results: VEGF-A and VEGF-C are overexpressed in LNM. VEGF-A was associated with patient age $(p<0.001)$, and VEGFR-2 and VEGFR-3 with CRC relapse ( $p=0.032 ; p=0.030$, respectively). VEGF-C positivity was associated with VEGFR-3 positivity $(p=0.031)$, and VEGF-D with VEGFR-2 and VEGFR-3 ( $p \leq 0.001)$. Matching the expression in LNM with CRC, in CRC VEGF-A positivity associates with VEGF-A, VEGF-C, VEGF-D, VEGF-R2, VEGF-R3 positivity in LNM; CRC VEGF-C with VEGF-D, VEGFR-2, VEGFR-3; CRC VEGFR-2 with VEGF-A, VEGF-C, VEGF-D, VEGFR-2, VEGFR-3; CRC VEGFR-3 with VEGF-A, VEGF-C, VEGF-D, VEGFR-2, VEGFR-3 in LNM. Conclusion: This study provides new information, revealing that VEGF family expression is increased in LNM. The association between the expression of VEGFR-2 and VEGFR-3 in LNM with CRC relapse reveals its impact on patient prognosis. Interesting data were found when the relationship between these proteins in primary tumor and their metastasis, were analyzed; VEGFA positivity in primary tumor is positively related to VEGF-A, VEGF-C, VEGF-D, VEGFR-2 and VEGFR-3 in their respective LNM suggesting mutual influence.
\end{abstract}

Keywords: colorectal cancer; lymph node metastasis; VEGF

\section{Introduction}

Colorectal cancer (CRC) is the third most common cancer and the fourth most frequent cause of cancer deaths worldwide [1], being one of the most prevalent diseases of the occidental world [2].

There are some well-established prognostic factors in CRC. Pre-operative tumor staging provides essential and relevant prognostic information for choosing adequate therapeutic proceeding, being the factor that best predicts patient survival [3]. Other robust determinants of prognosis include lymphovascular invasion, positive surgical margins, pre-operative increasing of carcinoembryonic 
antigen (CEA) [4]. However, although these clinicopathological parameters determine the management of patients, they are not reliable predictors of treatment outcome. Hence, in order to improve clinical care and patient's survival, the molecular pathways of cancer dissemination and their biological markers expression should be identified [1].

Angiogenesis plays an important role in tumorigenesis and metastatic progression of cancer [5]. Actually, the relationship between tumor angiogenesis with the grade of tumor differentiation, its metastatic potential and prognosis is mentioned in several studies [5]. Neovascularization promotes tumor growth by supplying nutrients, oxygen and releasing growth factors that promote tumor cell proliferation [6]. Furthermore, the immature neovasculature facilitates cancer cell entry into the systemic blood circulation and hence distant metastasis [7].

The regulation of tumor angiogenesis depends on a complex balance between angiogenic and antiangiogenic factors, secreted by both tumor cells and immune host-infiltrating cells as well as by tumoral stroma-cells [5-7]. The understanding of the fundamental role of angiogenesis in cancer growth and metastasis has led to tremendous interest in research in its regulatory mechanisms and clinical implications in the management of cancer treatment.

Vascular endothelial growth factor (VEGF) is the most widely studied and best characterized angiogenic factor, secreted by almost all solid cancers [6,7]. It stimulates endothelial proliferation and migration, vascular permeability and is the most potent angiogenic protein known [5,6,8-10]. The effect of VEGF depends on tumor cell expression of VEGF and its receptors in the endothelial cells [11]. The ligands of the VEGF family include VEGF-A, VEGF-B, VEGF-C, VEGF-D and VEGF-E and their receptors (VEGFR-1, VEGFR-2, and VEGFR-3) [12].

When overexpressed, VEGF is associated with advanced tumor stage or tumor invasiveness in various types of human cancer [13]. CRC growth and spread are dependent on angiogenesis with VEGF being the most important cytokine involved in the process [8].

Both VEGF and its receptors are expressed at high levels in metastatic CRC and in tumor-associated endothelial cells, respectively. VEGF expression is higher in patients with metastatic tumors than in those with non-metastatic tumors [9]. However, the relationship between VEFG tumor expression and CRC outcomes is controversial. While some studies show that VEGF expression has no significant prognostic value [10,13-15], others, have demonstrated that the VEGF overexpression in colonic cancer tissue and lymph nodes indicates more advanced cancer stage and poor prognosis [13,16].

Our previous study reported that the expression of VEGF in the primary tumor was associated with poor prognosis and reduced patient survival with CRC [13]. This finding was also reinforced by other studies that consider VEGF expression as a useful marker for prognosis due to its correlation with angio-lymphatic invasion, lymph node status and depth of local invasion $[5,13]$. Therefore, it becomes relevant to evaluate VEGF status in LNM of CRC patients and correlate this expression in lymph node with primary tumor and clinicopathological characteristics and disease outcome.

\section{Results}

\subsection{Characterization of the Sample}

Table 1 describes the clinicopathological data and follow-up results of the 210 patients with diagnosis of CRC with lymph node metastasis. 
Table 1. Clinicopathological characterization of sample.

\begin{tabular}{|c|c|c|}
\hline \multicolumn{2}{|c|}{ Clinical Data and Pre-Operative Exams Results } & \multirow{2}{*}{$\begin{array}{c}n \mathbf{n}(\%) \\
131(62.4)\end{array}$} \\
\hline Gender & Male & \\
\hline & Female & $79(37.6)$ \\
\hline \multirow[t]{2}{*}{ Age (years) } & $\leq 45$ & $15(7.1)$ \\
\hline & $>45$ & $195(92.9)$ \\
\hline \multirow{2}{*}{ Personal history of CRC } & Negative & $182(86.7)$ \\
\hline & Positive & $28(13.3)$ \\
\hline \multirow[t]{2}{*}{ Familiar history of CRC } & Negative & $172(81.9)$ \\
\hline & Positive & $22(10.5)$ \\
\hline \multirow{2}{*}{ Clinical presentation } & Asymptomatic & 37 (17.6) \\
\hline & Symptomatic & $173(82.4)$ \\
\hline \multirow[t]{3}{*}{ Tumor localization } & Right colon & $50(23.8)$ \\
\hline & Left colon & $111(52.9)$ \\
\hline & Rectum & 49 (23.3) \\
\hline \multirow[t]{2}{*}{ Preoperative value of CEA } & $\leq 10 \mathrm{ng} / \mathrm{mL}$ & $134(63.8)$ \\
\hline & $>10 \mathrm{ng} / \mathrm{mL}$ & $38(18.1)$ \\
\hline \multirow[t]{2}{*}{ Metastasis at diagnosis } & Yes & $70(33.3)$ \\
\hline & No & $140(66.7)$ \\
\hline \multicolumn{3}{|c|}{ Histopathological report } \\
\hline \multirow[t]{2}{*}{ Tumor size $(\mathrm{mm})$} & $\leq 45$ & $118(56.2)$ \\
\hline & $>45$ & $79(37.6)$ \\
\hline \multirow[t]{5}{*}{ Tumor Macroscopic aspect } & Polypoid & $91(43.3)$ \\
\hline & Ulcerative & $53(25.2)$ \\
\hline & Infiltrative & $19(9)$ \\
\hline & Exophytic & $23(11)$ \\
\hline & Vilosous & $1(0.5)$ \\
\hline \multirow[t]{3}{*}{ Tumor Histological type } & Adenocarcinoma & $179(85.2)$ \\
\hline & Mucinous & $27(12.9)$ \\
\hline & Signet ring cells and mucinous areas & $4(1.9)$ \\
\hline \multirow[t]{5}{*}{ Tumor differentiation } & Well & $74(35.2)$ \\
\hline & Moderate & 93 (44.3) \\
\hline & Poor & 37 (17.6) \\
\hline & Undifferentiated & $2(1)$ \\
\hline & Unknown & $4(1.9)$ \\
\hline \multirow[t]{2}{*}{ Invasion of lymphatic vessels } & Absent & $19(9)$ \\
\hline & Present & $172(82)$ \\
\hline \multirow[t]{2}{*}{ Invasion of venous vessels } & Absent & $70(33.3)$ \\
\hline & Present & $132(62.9)$ \\
\hline \multirow[t]{3}{*}{ Tumor staging } & Stage III & $160(76.2)$ \\
\hline & Stage IV & $50(23.8)$ \\
\hline & Follow-up data & \\
\hline \multirow[t]{2}{*}{ Relapse } & Yes & $45(21.4)$ \\
\hline & No & $165(78.6)$ \\
\hline \multirow[t]{2}{*}{ Death } & Alive & $106(50.5)$ \\
\hline & Dead & $104(49.5)$ \\
\hline
\end{tabular}

2.2. VEGF-A, VEGF-C, VEGF-D, VEGFR-2 and VEGFR-3 Expression in CRC Lymph Nodes Metastasis

Table 2 summarizes the frequency of VEGF-A, VEGF-C, VEGF-D, VEGFR-2 and VEGFR-3 positive expression in lymph nodes metastasis of CRC. VEGF-A was positively expressed in $59.0 \%$ of the evaluated cases, followed by VEGF-C in $54.8 \%$ of the cases. 
Table 2. Frequencies of positive VEGF family immunoreactions in the CRC LNM.

\begin{tabular}{ccc}
\hline \multirow{2}{*}{ Protein Marker } & \multicolumn{2}{c}{ Immunoreaction } \\
\cline { 2 - 3 } & $\boldsymbol{n}$ & $\boldsymbol{n}$ Positive (\%) \\
\hline VEGF-A & 136 & $124(59.0 \%)$ \\
VEGF-C & 133 & $115(54.8 \%)$ \\
VEGF-D & 113 & $88(41.9 \%)$ \\
VEGFR-2 & 64 & $53(25.2 \%)$ \\
VEGFR-3 & 104 & $83(39.5 \%)$
\end{tabular}

$n$ : total number of cases with and without VEGF expression; $n$ positive (\%): total number of cases with VEGF expression and respective percentage.

Figure 1 shows representative positive staining for VEGF-A, VEGF-C, VEGF-D, VEGFR-2 and VEGFR-3.

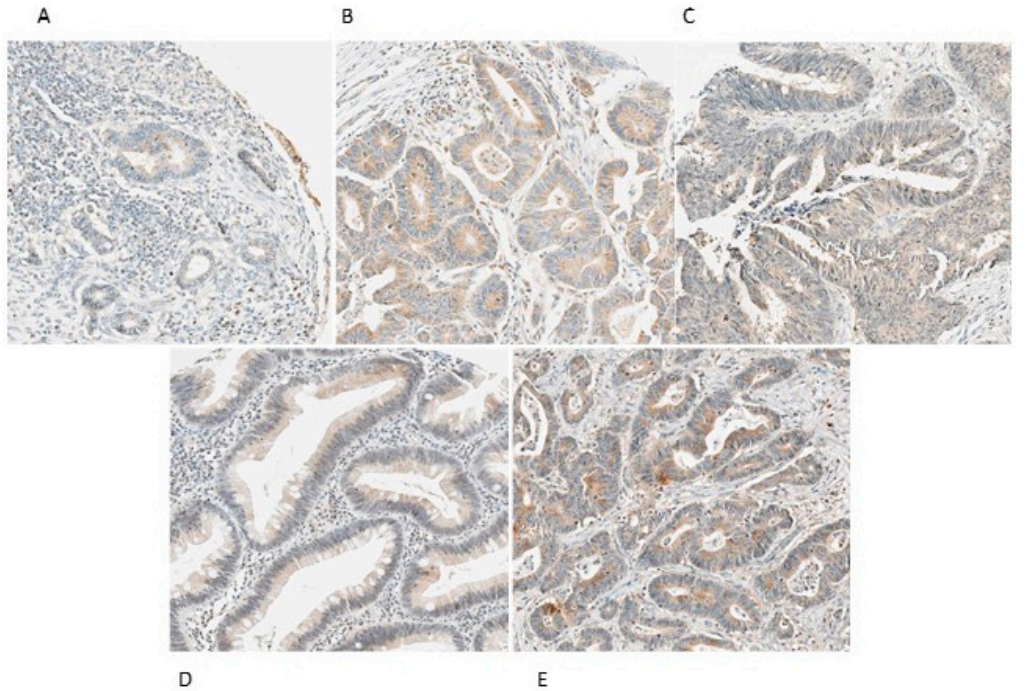

Figure 1. Immunohistochemical expression of VEGF-A, VEGF-C, VEGF-R2 and VEGF-R3 in. RC LNM samples (original magnification $\times 100$ ). (A) positive immunohistochemical expression of VEGF-A with intensity 2 and extension 1; (B) positive immunohistochemical expression of VEGF-C with intensity 3 and extension 3; (C) positive immunohistochemical expression of VEGF-D with intensity 2 and extension 3; (D) positive immunohistochemical expression of VEGFR-2 with intensity 2 and extension 3 and (E) positive immunohistochemical expression of VEGFR-3 with intensity 3 and extension 3.

2.3. Associations between VEGF-A, VEGF-C, VEGF-D, VEGFR-2 and VEGFR-3 Expression in Lymph Nodes Metastasis of CRC and Clinicopathological Characteristics

In order to assess the value of the expression of these angiogenic factors, we sought for associations with the patients clinicopathological data. An assessment of the correlation between the expression of VEGF-A, VEGF-C, VEGF-D, VEGFR-2 and VEGFR-3 and the clinical data revealed a significant association $(p=0.001)$ between VEGF-A expression and patient age, which was greater in patients aged older than 45 years (93.8\%) compared to patients younger or with 45 years old (42.9\%). There is also an association between the expression of VEGFR-2 $(p=0.032)$ and VEGFR-3 $(p=0.030)$ with CRC relapse. No significant relationship was found for the other analyzed parameters. These results are shown in Table 3.

When analysing the correlation between these markers with data from diagnosis/surgery, like patient gender and age, personal or familiar history and follow-up data like relapse and death no significant association was found, as observed in Table 4.

When analysing the correlation between these markers with data from pathological data, no significant association was found, as observed in Table 5. 
Table 3. Assessment of correlation between CRC lymph node metastasis VEGF-A, VEGF-C, VEGF-D, VEGFR-2 and VEGFR-3 expression and clinical data. * Examined for statistical significance using Fisher's exact test (when $n<5$ ). In bold the significant results.

\begin{tabular}{|c|c|c|c|c|c|c|c|c|c|c|c|c|c|c|c|}
\hline \multirow{2}{*}{ Protein Marker } & \multicolumn{3}{|c|}{ VEGF-A } & \multicolumn{3}{|c|}{ VEGF-C } & \multicolumn{3}{|c|}{ VEGF-D } & \multicolumn{3}{|c|}{ VEGFR-2 } & \multicolumn{3}{|c|}{ VEGFR-3 } \\
\hline & $n$ & $\begin{array}{c}\text { Positive } \\
\text { (\%) }\end{array}$ & $p$ & $n$ & $\begin{array}{c}\text { Positive } \\
\text { (\%) }\end{array}$ & $p$ & $n$ & $\begin{array}{c}\text { Positive } \\
(\%)\end{array}$ & $p$ & $n$ & $\begin{array}{c}\text { Positive } \\
(\%)\end{array}$ & $p$ & $n$ & $\begin{array}{c}\text { Positive } \\
\text { (\%) }\end{array}$ & $p$ \\
\hline \multicolumn{16}{|l|}{ Gender } \\
\hline Male & 83 & 92.8 & \multirow{2}{*}{0.412} & 86 & 84.9 & \multirow{2}{*}{0.471} & 75 & 76 & \multirow{2}{*}{0.5} & 41 & 78 & \multirow{2}{*}{0.301 * } & 67 & 77.6 & \multirow{2}{*}{0.453} \\
\hline $\begin{array}{l}\text { Female } \\
\text { Age, years }\end{array}$ & 53 & 88.7 & & 47 & 89.4 & & 38 & 81.6 & & 23 & 91.3 & & 37 & 83.8 & \\
\hline$\leq 45$ & 7 & 42.9 & \multirow{2}{*}{$0.001 *$} & 9 & 88.9 & \multirow{3}{*}{$1.000 *$} & 10 & 70 & \multirow{3}{*}{0.689 * } & 6 & 83.3 & \multirow{3}{*}{$1.000 *$} & 8 & 87.5 & \multirow{2}{*}{$1.000 *$} \\
\hline$>45$ & 129 & 93.8 & & 124 & 86.3 & & 103 & 78.6 & & 58 & 82.8 & & 96 & 79.2 & \\
\hline CRC Personal history & & & & & & & & & & & & & & & \\
\hline $\begin{array}{l}\text { Negative } \\
\text { Positive }\end{array}$ & $\begin{array}{c}133 \\
3\end{array}$ & $\begin{array}{c}91 \\
100\end{array}$ & \multirow[t]{2}{*}{1.000 * } & $\begin{array}{c}130 \\
3\end{array}$ & $\begin{array}{l}86.2 \\
100\end{array}$ & \multirow[t]{2}{*}{$1.000 *$} & $\begin{array}{c}110 \\
3\end{array}$ & $\begin{array}{l}77.3 \\
100\end{array}$ & \multirow[t]{2}{*}{$1.000 *$} & $\begin{array}{c}63 \\
1\end{array}$ & $\begin{array}{l}82.5 \\
100\end{array}$ & \multirow[t]{2}{*}{$1.000 *$} & $\begin{array}{c}101 \\
3\end{array}$ & $\begin{array}{c}79 \\
100\end{array}$ & \multirow[t]{2}{*}{$1.000 *$} \\
\hline CRC Familiar history & & & & & & & & & & & & & & & \\
\hline Negative & 112 & 90.2 & \multirow[b]{2}{*}{$0.603 *$} & 109 & 87.2 & \multirow[b]{2}{*}{$1.000 *$} & 91 & 79.1 & \multirow{3}{*}{0.218} & 53 & 81.1 & \multirow{3}{*}{1.000 * } & 82 & 80.5 & \multirow[b]{2}{*}{0.504 * } \\
\hline Positive & 13 & 100 & & 15 & 86.7 & & 14 & 64.3 & & 9 & 88.9 & & 15 & 73.3 & \\
\hline Relapse & & & & & & & & & & & & & & & \\
\hline No & 110 & 91.8 & \multirow{2}{*}{0.699 * } & 111 & 86.5 & \multirow{3}{*}{1.000 * } & 94 & 80.9 & \multirow{3}{*}{0.09} & 59 & 86.4 & \multirow{3}{*}{$0.032 *$} & 86 & 83.7 & \multirow{3}{*}{0.03} \\
\hline Yes & 26 & 88.5 & & 22 & 86.4 & & 19 & 63.2 & & 5 & 40 & & 18 & 61.1 & \\
\hline Death & & & & & & & & & & & & & & & \\
\hline Alive & 92 & 91.3 & $1.000 *$ & 89 & 86.5 & & 75 & 78.7 & & 49 & 87.8 & & 68 & 80.9 & 0.708 \\
\hline Dead & 44 & 90.9 & $1.000^{*}$ & 44 & 86.4 & 0.981 & 38 & 76.3 & 0.776 & 15 & 66.7 & 0.058 & 36 & 77.8 & 0.708 \\
\hline
\end{tabular}


Table 4. Assessment of correlation between CRC lymph node metastasis VEGF-A, VEGF-C, VEGF-D, VEGFR-2 and VEGFR-3 expression and diagnostic/surgical data. * Examined for statistical significance using Fisher's exact test (when $n<5$ ).

\begin{tabular}{|c|c|c|c|c|c|c|c|c|c|c|c|c|c|c|c|}
\hline \multirow{2}{*}{ Protein Marker } & \multicolumn{3}{|c|}{ VEGF-A } & \multicolumn{3}{|c|}{ VEGF-C } & \multicolumn{3}{|c|}{ VEGF-D } & \multicolumn{3}{|c|}{ VEGFR-2 } & \multicolumn{3}{|c|}{ VEGFR-3 } \\
\hline & $n$ & $\begin{array}{c}\text { Positive } \\
(\%)\end{array}$ & $p$ & $n$ & $\begin{array}{c}\text { Positive } \\
\text { (\%) }\end{array}$ & $p$ & $n$ & $\begin{array}{c}\text { Positive } \\
(\%)\end{array}$ & $p$ & $n$ & $\begin{array}{c}\text { Positive } \\
(\%)\end{array}$ & $p$ & $n$ & $\begin{array}{c}\text { Positive } \\
\text { (\%) }\end{array}$ & $p$ \\
\hline \multicolumn{16}{|l|}{ Presentation } \\
\hline Asymptomatic & 25 & 88 & \multirow{3}{*}{0.462 * } & 22 & 86.4 & \multirow{3}{*}{$1.000 *$} & 15 & 80 & \multirow{3}{*}{$1.000 *$} & 14 & 78.6 & \multirow{3}{*}{0.693 * } & 17 & 88.2 & \multirow{3}{*}{$0.513 *$} \\
\hline Symptomatic & 111 & 91.9 & & 111 & 86.5 & & 98 & 77.6 & & $\begin{array}{l}14 \\
50\end{array}$ & 84 & & 87 & $\begin{array}{l}0.2 \\
78.2\end{array}$ & \\
\hline Localization & & & & & & & & & & & & & & & \\
\hline Right Colon & 31 & 93.5 & \multirow{3}{*}{0.772} & 35 & 85.7 & \multirow{4}{*}{0.152} & 31 & 80.6 & \multirow{4}{*}{0.84} & 18 & 88.9 & \multirow{4}{*}{0.414} & 32 & 78.1 & \multirow{3}{*}{0.213} \\
\hline Left Colon & 70 & 91.4 & & 68 & 91.2 & & 59 & 78 & & 35 & 77.1 & & 50 & 86 & \\
\hline Rectum & 35 & 88.6 & & 30 & 76.7 & & 23 & 73.9 & & 11 & 90.9 & & 22 & 68.2 & \\
\hline \multicolumn{13}{|l|}{ Metastasis } & & & \\
\hline Not present & 91 & 91.2 & \multirow{3}{*}{1.000 * } & 87 & 87.4 & \multirow{3}{*}{0.68} & 73 & 79.5 & \multirow{3}{*}{0.586} & 39 & 87.2 & \multirow{3}{*}{0.247} & 67 & 74.6 & \multirow{3}{*}{$0.124^{*}$} \\
\hline Present & 45 & 91.1 & & 46 & 84.8 & & 40 & 75 & & 25 & 76 & & 37 & 89.2 & \\
\hline \multicolumn{11}{|c|}{ Macroscopic Appearance } & & & & & \\
\hline $\begin{array}{l}\text { Polypoid } \\
\text { SPPat }\end{array}$ & 60 & 98.3 & & 57 & 86 & & 48 & 79.2 & & 23 & 95.7 & & 40 & 75 & \\
\hline Ulcerative & 35 & 82.9 & \multirow{4}{*}{0.072} & 30 & 93.3 & \multirow{4}{*}{0.737} & 28 & 71.4 & \multirow{4}{*}{0.417} & 24 & 75 & \multirow{4}{*}{0.383} & 30 & 86.7 & \multirow{4}{*}{0.083} \\
\hline Infiltrative & 15 & 86.7 & & 13 & 84.6 & & 10 & 100 & & 5 & 80 & & 11 & 90.9 & \\
\hline Exophytic & 10 & 80 & & 15 & 80 & & 14 & 78.6 & & 5 & 80 & & 12 & 50 & \\
\hline Vilosous & 1 & 100 & & 1 & 100 & & 1 & 100 & & 1 & 100 & & 1 & 100 & \\
\hline \multicolumn{16}{|l|}{$\operatorname{CEA}(\mathrm{ng} / \mathrm{mL})$} \\
\hline$\leq 10$ & 88 & 93.2 & \multirow[b]{2}{*}{0.424 * } & 82 & 86.6 & & 68 & 77.9 & & 42 & 81 & & 62 & 79 & \\
\hline$>10$ & 26 & 88.5 & & 25 & 88 & 1.000 * & 21 & 85.7 & 0.546 * & 12 & 91.7 & 0.665 * & 22 & 86.4 & $0.543^{*}$ \\
\hline
\end{tabular}


Table 5. Assessment of correlation between CRC lymph node metastasis VEGF-A, VEGF-C, VEGF-D, VEGFR-2 and VEGFR-3 pathological data. ${ }^{*}$ Examined for statistical significance using Fisher's exact test (when $n<5$ ).

\begin{tabular}{|c|c|c|c|c|c|c|c|c|c|c|c|c|c|c|c|}
\hline \multirow{2}{*}{ Protein Marker } & \multicolumn{3}{|c|}{ VEGF-A } & \multicolumn{3}{|c|}{ VEGF-C } & \multicolumn{3}{|c|}{ VEGF-D } & \multicolumn{3}{|c|}{ VEGFR-2 } & \multicolumn{3}{|c|}{ VEGFR-3 } \\
\hline & $n$ & $\begin{array}{l}\text { Positive } \\
\text { (\%) }\end{array}$ & $p$ & $\mathrm{n}$ & $\begin{array}{c}\text { Positive } \\
(\%)\end{array}$ & $p$ & $n$ & $\begin{array}{c}\text { Positive } \\
(\%)\end{array}$ & $p$ & $n$ & $\begin{array}{c}\text { Positive } \\
(\%)\end{array}$ & $p$ & $n$ & $\begin{array}{c}\text { Positive } \\
(\%)\end{array}$ & $p$ \\
\hline \multicolumn{16}{|l|}{ Tumor size $(\mathrm{cm})$} \\
\hline$\leq 4.5$ & 72 & 91.7 & \multirow{3}{*}{0.905} & 73 & 89 & \multirow{2}{*}{0.329} & 62 & 83.9 & \multirow{3}{*}{0.101} & 38 & 89.5 & \multirow{3}{*}{0.096 * } & 57 & 86 & \multirow[b]{2}{*}{0.145} \\
\hline$>4.5$ & 56 & 91.1 & & 53 & 83 & & 48 & 70.8 & & 25 & 72 & & 43 & 74.4 & \\
\hline \multicolumn{13}{|l|}{ Histological Type } & & & \\
\hline Adenocarcinoma & 119 & 91.6 & \multirow{4}{*}{0.741} & 114 & 87.7 & \multirow{4}{*}{0.383} & 95 & 77.9 & & 52 & 82.7 & & 90 & 81.1 & \\
\hline Mucinous & 15 & 86.7 & & 17 & 76.5 & & 16 & 75 & \multirow[t]{2}{*}{0.724} & 11 & 81.8 & \multirow[t]{3}{*}{0.898} & 13 & 69.2 & \multirow[t]{2}{*}{0.535} \\
\hline $\begin{array}{l}\text { Signet ring cells and } \\
\text { mucinous areas }\end{array}$ & 2 & 100 & & 2 & 100 & & 2 & 100 & & 1 & 100 & & 1 & 100 & \\
\hline \multicolumn{13}{|l|}{ Differentiation } & & & \\
\hline Well & 54 & 92.6 & \multirow{5}{*}{0.773} & 52 & 88.5 & \multirow{5}{*}{0.91} & 42 & 78.6 & \multirow{5}{*}{0.283} & 24 & 87.5 & \multirow{5}{*}{0.731} & 41 & 82.9 & \multirow{4}{*}{0.105} \\
\hline Moderate & 60 & 88.3 & & 55 & 87.3 & & 49 & 83.7 & & 29 & 79.3 & & 43 & 83.7 & \\
\hline Poor & 19 & 94.7 & & 24 & 83.3 & & 21 & 66.7 & & 11 & 81.8 & & 19 & 68.4 & \\
\hline Undifferentiated & 1 & 100 & & 1 & 100 & & 0 & 0 & & 0 & 0 & & 1 & 0 & \\
\hline Lymph invasion & & & & & & & & & & & & & & & \\
\hline Absent & 12 & 91.7 & \multirow{2}{*}{$1.000 *$} & 11 & 100 & \multirow{2}{*}{$0.360^{*}$} & 7 & 85.7 & \multirow{2}{*}{$1.000 *$} & 2 & 100 & \multirow{2}{*}{$1.000 *$} & 8 & 87.5 & \multirow{2}{*}{$1.000 *$} \\
\hline $\begin{array}{l}\text { Present } \\
\text { Venous invasion }\end{array}$ & 109 & 89.9 & & 110 & 84.5 & & 93 & 78.5 & & 58 & 81 & & 83 & 79.5 & \\
\hline $\begin{array}{l}\text { Venous invasion } \\
\text { Absent }\end{array}$ & 44 & 95.5 & \multirow{2}{*}{$0.217^{*}$} & 39 & 84.6 & & 31 & 77.4 & & 19 & 84.2 & & 29 & 75.9 & \\
\hline Present & 84 & 88.1 & & 87 & 87.4 & 0.677 & 75 & 77.3 & 0.992 & 42 & 81 & $1.000^{*}$ & 68 & 80.9 & 0.576 \\
\hline TNM stage & & & & & & & & & & & & & & & \\
\hline Stage III & 104 & 89.4 & $0293 *$ & 97 & 85.6 & $0779^{*}$ & 80 & 77.5 & 0881 & 47 & 83 & $1000 *$ & 73 & 80.8 & 0693 \\
\hline Stage IV & 32 & 96.9 & $0.293^{\circ}$ & 36 & 88.9 & $0.7 / 99^{\circ}$ & 33 & 78.8 & 0.881 & 17 & 82.4 & $1.000^{*}$ & 31 & 77.4 & 0.693 \\
\hline
\end{tabular}


2.4. Associations Between VEGF-A, VEGF-C, VEGF-D and VEGFR-2, VEGFR-3 Expression in Lymph Nodes of $C R C$

In order to look for the existence of some association, we matched the expression of this angiogenic related-proteins (VEGF-A, VEGF-C, VEGF-D) with their receptors (VEGFR-2 and VEGFR-3) in metastatic CRC lymph nodes and we observed that VEGF-C positivity was associated with VEGFR-3 positivity $(p=0.031)$, as well as VEGR-D positivity was associated with VEGFR-2 $(p \leq 0.001)$ and VEGFR-3 ( $p=0.001)$ positivity, Table 6.

Table 6. Assessment of associations between expression of VEGF-A, VEGF-C and VEGF-D and the receptors VEGFR-2 and VEGFR-3 in lymph node metastasis of CRC. * Examined for statistical significance using Fisher's exact test (when $n<5$ ). In bold the significant results.

\begin{tabular}{|c|c|c|c|c|c|c|}
\hline & \multicolumn{3}{|c|}{ VEGFR-2 } & \multicolumn{3}{|c|}{ VEGFR-3 } \\
\hline & $n$ Positive (\%) & $n$ & $p$-Value & $n$ Positive (\%) & $n$ & $p$-Value \\
\hline VEGF-A & 39 (81.3) & 48 & 0.649 * & $58(79.5)$ & 73 & $1.000 *$ \\
\hline VEGF-C & 48 (87.3) & 55 & $\#$ & 77 (83.7) & 92 & $0.031 *$ \\
\hline VEGF-D & $45(97.8)$ & 46 & 0.000 * & $69(88.5)$ & 78 & 0.001 \\
\hline
\end{tabular}

2.5. Association between VEGF-A, VEGF-C, VEGF-D and VEGFR-2, VEGFR-3 Expression in CRC Primary Tumor and Respective Lymph Nodes Metastasis

With the intention to evaluate the potential relationship of the expression of these angiogenic factors and receptors in tumor and lymph node samples that belongs to the same patient, we analyzed the overall results depicted in Table 7 .

Table 7. Pattern of protein staining in primary tumor versus the respective metastatic lymph nodes in CRC. In bold the significant results.

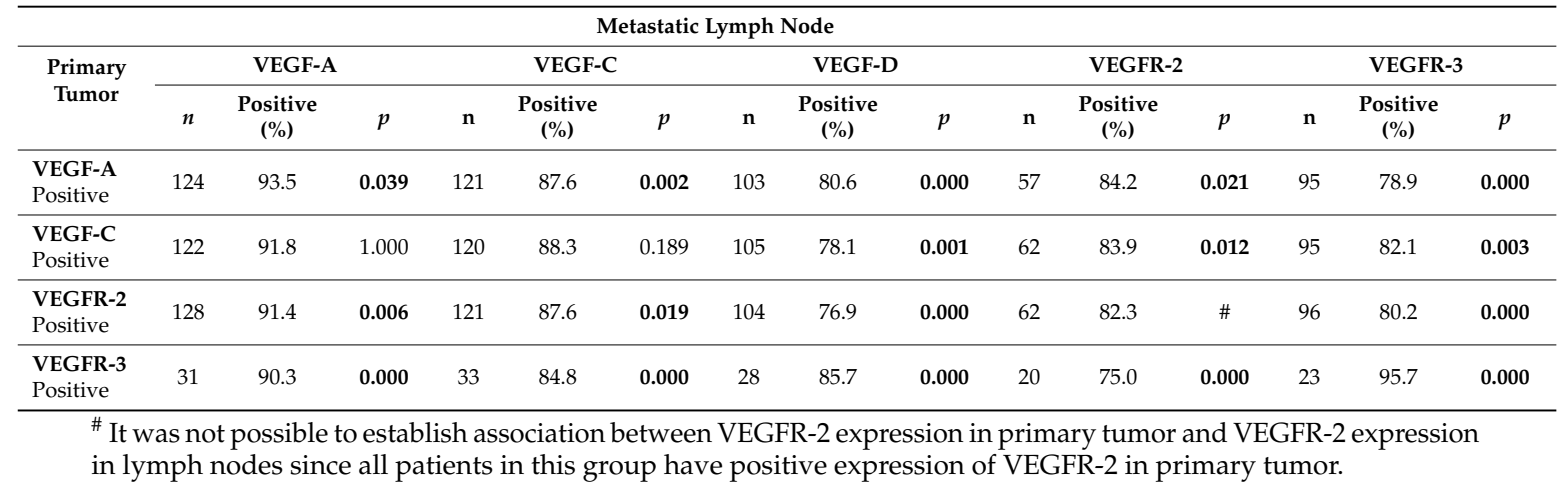

It can be seen that VEGF-A positivity in CRC primary tumor samples associates with VEGF-A $(p=0.039)$, VEGF-C ( $p=0.002), \operatorname{VEGF-D}(p \leq 0.001), \operatorname{VEGFR}-2(p=0.021)$ and VEGFR-3 $(p \leq 0.001)$ positivity in their respective lymph node metastasis; VEGF-C in primary tumor and VEGF-D $(p=0.001)$, VEGFR-2 ( $p=0.012)$ and VEGFR-3 ( $p=0.003)$; VEGFR-2 expression in CRC and VEGF-A $(p=0.006)$, VEGF-C ( $p=0.019)$, VEGF-D ( $p \leq 0.001)$, VEGFR-2 (\#) and VEGFR-3 ( $p \leq 0.001)$ in their lymph nodes; VEGFR-3 in CRC tissues and VEGF-A $(p \leq 0.001)$, VEGF-C $(p \leq 0.001)$, VEGF-D $(p \leq 0.001)$, VEGFR-2 $(p \leq 0.001)$ and VEGFR-3 $(p \leq 0.001)$ in lymph nodes. 
2.6. Lack of Relationship between Overall CRC Survival and Expression of VEGF-A,VEGF-C, VEGF-D, VEGFR-2 and VEGFR-3 in CRC Lymph Nodes Metastasis

Kaplan-Meier survival curves were built to evaluate the correlation between the expression of VEGF-A, VEGF-C, VEGF-D, VEGFR-2 and VEGFR-3 in CRC lymph nodes metastasis and their survival (Table 8).

Table 8. Relation between VEGF expression in CRC lymph node metastasis and survival.

\begin{tabular}{ccccc}
\hline $\begin{array}{l}\text { Protein } \\
\text { Marker }\end{array}$ & $N$ & $n$ of Deaths (\%) & $\begin{array}{c}\text { Average for Survival Time } \\
{[\mathbf{9 5 \%} \text { CI] }}\end{array}$ & $\begin{array}{c}p \\
\text { (Log-Rank Test) }\end{array}$ \\
\hline VEGF-A & & & & \\
Positive & 124 & $40(32.26 \%)$ & $65.01[58.86-71.17]$ & 0.748 \\
Negative & 12 & $4(33.33 \%)$ & $57.89[37.15-78.63]$ & \\
VEGF-C & & & & \\
Positive & 115 & $38(33.04 \%)$ & $63.61[56.74-70.47]$ & 0.824 \\
Negative & 18 & $6(33.33 \%)$ & $65.31[49.74-80.97]$ & \\
VEGF-D & & & & \\
Positive & 88 & $29(32.95 \%)$ & $62.21[54.54-69.87]$ & \\
Negative & 25 & $9(36.00 \%)$ & $53.25[39.85-66.66]$ & \\
VEGFR-2 & & & & \\
Positive & 53 & $10(1.89 \%)$ & $50.26[50.22-62.31]$ & \\
Negative & 11 & $5(4.55 \%)$ & $34.03[22.00-46.06]$ & \\
VEGFR-3 & & & & \\
Positive & 83 & $28(3.37 \%)$ & $62.81[54.66-70.97]$ & \\
Negative & 21 & $8(3.81 \%)$ & $57.17[41.84-72.50]$ & \\
\hline
\end{tabular}

When analysing the survival curves, no significant associations were found between the expression of the different VEGF in lymph nodes of CRC and survival of the patients.

\section{Discussion}

There are several data highlighting the essential role of angiogenesis in tumorigenesis, metastization and prognosis [5]. CRC growth and spread are especially dependent on angiogenesis, where VEGF play an important role in this process [8]. However, the relationship between VEFG tumor expression and CRC outcomes is controversial. We documented previously that the quantification of VEGF-A, VEGF-C, VEGFR-2 and VEGFR-3 expression in primary tumor of CRC provide valuable prognostic information with confident correlation with clinicopathological data, showing with the principal characteristics that contribute poor survival rates and prognosis [13].

Following our earlier study insights that evaluated VEGF family expression in the primary tumor, we sought to investigate the expression of VEGF-A, C, D and VEGFR-2 and VEGFR-3 in CRC lymph nodes and to correlate this expression with clinical and prognostic parameters of the same patient group [13].

Similarly to literature data, which states that VEGF-A is the most abundantly expressed ligand of the VEGF family in primary tumor of CRC [6,8], the pattern of protein staining in lymph nodes also showed positive expression of VEGF-A in $60 \%$ of CRC metastatic to lymph nodes. However, in our previous study, VEGF-A expression in tumor cells was not significantly higher than its expression in normal adjacent epithelium [13]. Other studies have shown a higher expression of VEGF-A in patients with metastatic tumors as well as in those with non-metastatic tumors [6,9,13,17] and a significant correlation with angio-lymphatic invasion, lymph node status and depth of invasion $[8,13,18]$. However, as all patients included in our study had a histological diagnosis of colorectal adenocarcinoma associated with positive lymph nodes, the potential comparison with these observations was impaired.

Additionally, we observed significant positive expression of VEGF-C (54.8\%), VEGF-D (41.9\%) and the receptor VEGFR-3 (39.5\%), all of these factors particularly involved in lymphangiogenesis and lymph node invasion of tumors [19]. The lowest percentage of expression was observed for 
VEGFR-2 receptor (25.2\%), a receptor that regulates endothelial proliferation and migration and most significantly involved in the process of angiogenesis $[19,20]$. Since the expression of these factors was exclusively focused in lymph nodes of CRC, it seems logical to have a higher percentage of expression of factors involved in the lymphangiogenesis process (VEGF-C, D, R3). In our previous study, when VEGF expression was compared in tumor cells and normal adjacent epithelium, only VEGF-C appeared to be expressively overexpressed in tumor cells and VEGFR-2 showed a tendency for an analogous association.

VEGF-A expression in CRC lymph nodes was found to be significantly related $(p=0.0001)$ to the patient's age, with patients aged 45 years or older, showing tumors with the highest expression of VEGF-A (92.4\%). However, this finding contradicts the literature data that describes a decline in the expression of VEGF family factors with age [21-23]; this can be explicated by the fact that the number of patients aged less than 45 years $(n=8)$ is much lower than the number of patients aged 45 years or older $(n=131)$, so an enlargement of the sample could be useful to test this hypothesis.

It was also observed that the expressions of VEGFR-2 $(p=0.032)$ and VEGFR-3 $(p=0.034)$ receptors in the lymph nodes of CRC patients were significantly related to cancer recurrence. Although scarce, some literature data endorse these findings, since they assign to the presence of angiogenic cytokine receptors an increased risk of relapse of several types of cancer [24-26]. In view of this finding, it may be important to implement a tighter follow-up plan for patients with positive expression of VEGFR-2 and VEGFR-3 receptors in the resected lymph nodes in order to make an earlier detection of cancer recurrence.

We analyzed the associations between expression of VEGF-A, VEGF-C, VEGF-D and the receptors VEGFR-2 and VEGFR-3 in CRC LNM samples and observed that VEGF-C positivity was associated with VEGFR-3 expression ( $p=0.031)$ and VEGR-D positive reactions were associated with VEGFR-2 $(p \leq 0.001)$ and VEGFR-3 ( $p=0.001)$ positivity; this is consistent with what is reported by other investigations showing that lymphangiogenesis induced by VEGF-C is predominantly driven by the activation of the tyrosine kinase-linked receptor VEGFR-3 [27]. Nevertheless, VEGF-C and VEGF-D have important roles in both angiogenesis and lymphangiogenesis, recognized as ligands of the tyrosine kinase receptors VEGFR-2, crucial for development of the blood vasculature, but also of the lymphatic vessels; moreover, VEGFR-3, primarily characterized as lymphangiogenic molecule, may also play decisive role in blood vessels growth [19].

VEGFR-3, restricted to lymphatic vessels in the final stages of development [15], and its ligands (VEGF-C and -D) stimulate lymphangiogenesis in tumors and induce proliferation and growth of new lymphatic capillaries, enhancing the incidence of LNM [13]. This is in agreement with the present study since all the patients with CRC included in the sample already had lymphatic spread of the tumor with positive lymph nodes.

When analyzing VEGF's expression and its receptors in lymph nodes and respectively primary tumor sample, we observed a significant association between the expression of VEGF-A in cancer tissue and the expression of VEGF-A in lymph nodes metastasis $(p=0.039)$. We can speculate a potential relationship between the cytokines produced in the primary tumor and those produced by the lymph nodes, creating an environment that supposedly promotes both tumor growth and lymphatic dissemination. We also found an interesting association between VEGF-A positivity in CRC samples and the expression of VEGF-C $(p=0.002)$, VEGF-D $(p \leq 0.001)$, VEGFR-2 $(p=0.021)$ and VEGFR-3 $(p \leq 0.001)$ in their respective lymph node metastasis. These findings reinforce the impression that the VEGF-A cytokine expressed by the primary tumor favor not only the growth and development of the primary tumor, but likewise its dissemination, stimulating the production of lymphangiogenic factors $[6,8,18]$.

Of note, we also found that VEGF-C expression in CRC are associated to the VEGF-D ( $p=0.001)$, VEGFR-2 $(p=0.012)$ and VEGFR-3 expression $(p=0.003)$ in CRC lymph node metastasis, which is in line with the mechanism of lymphangiogenesis and spread through lymphatic invasion. In CRC, augmented VEGF-C expression correlated with lymphatic invasion and lymph node metastasis, having 
as one of its receptors the VEGFR-3, expressed almost exclusively by lymphatic endothelium in adulthood [28].

Finally, we also observed a remarkable association between VEGFR-2 expression in the primary tumor and the expression of all angiogenic factors in their corresponding lymph node metastasis, VEGF-A $(p=0.006)$, VEGF-C ( $p=0.019)$, VEGF-D $(p=0.0001)$ and VEGFR-3 $(p=0.0001)$, as well as considerable association between VEGFR-3 expression in CRC as well as the expression of all VEGFs in the respective CRC lymph nodes infiltration: VEGF-A ( $p \leq 0.001)$, VEGF-C ( $p \leq 0.001)$, VEGF-D $(p \leq 0.001)$, VEGFR-2 $(p \leq 0.0011)$ and VEGFR-3 $(p \leq 0.0011)$. All these data alert us to the possibility that the production of these angiogenic factors by the lymph nodes can promote the progression and development of the primary tumor. Seems clear the ability to improve the tumor spread by the lymph nodes microenvironment, which reinforce the importance of its removal along with that of the tumor, is a way to avoid its local or distant recurrence. Our finding is also in accordance with literature that postulate that cancer cells infiltrated in lymph nodes and surrounding macrophages as well, continues to produce VEGFs ligand and receptors molecules even in metastatic field, which enhance the aggressiveness of the tumors and their potential of continuing dissemination of malignant cells $[29,30]$.

\section{Materials and Methods}

Population was constituted by 512 patients submitted to curative surgical intervention by CRC between 1st January of 2005 and 1st January of 2010.

CRC and lymph node samples were collected. Final sample was constituted by 210 patients with CRC with regional lymph node metastasis.

Data were collected prospectively, namely epidemiological data, clinical patient history, surgical and pathology records. Survival was actualized through follow-up evaluation in medical archives.

\subsection{CRC Primary Tumor and Metastasis Lymph Node Human Samples}

CRC tissue samples from the 512 patients were collected. The histological type of CRC was classified by an experienced pathologist and tumor staging was graded according to the TNM classification, 7th edition [31]. Tissue samples of CRC LNM were selected from the previous series, comprising 210 patients.

CRC samples and CRC LNM were included into tissue microarrays (TMAs). Prior to TMA construction, haematoxylin and eosin sections were reviewed to select representative areas of the tumor. Normal-adjacent tissue was also included in the TMAs for primary tumors. Each case was represented in the TMA by at least two cores of $0.6 \mathrm{~mm}$.

The study protocol was approved by the Ethics Committee of Hospital de Braga. The data of CRC and LNM series were collected prospectively, patients were informed and signed a written consensus for collecting data and samples collection.

\subsection{Immunohistochemistry}

Tissue microarray (TMA) protein expression was evaluated by immunohistochemistry. Briefly, after de-paraffinization and rehydration, $3 \mu \mathrm{m}$ sections were immersed in $0.01 \mathrm{M}$ citrate buffer ( $\mathrm{pH}$ 6.0) and heated at $98^{\circ} \mathrm{C}$ for $20 \mathrm{~min}$ for epitope antigen retrieval. Subsequently, endogenous peroxidase was blocked with $0.3 \%$ hydrogen peroxide in methanol. The primary antibody incubation step take place overnight at $4{ }^{\circ} \mathrm{C}$. Visualization was developed with 3,3'-diaminobenzidine (DAKO Corporation, Carpinteria, CA, USA) and counterstaining with Harris's haematoxylin (Merck, Dermstadt, Germany). Negative controls were obtained by omitting the primary antibody incubation step and tonsils were used as positive control. Details of the procedure used for each antibody are shown in Table 9. After the immunohistochemical procedure, the slides were evaluated and then photographed under microscope. 
Table 9. Detailed aspects of the immunohistochemical procedure used to visualize the different proteins.

\begin{tabular}{|c|c|c|c|c|c|c|}
\hline \multirow{2}{*}{$\begin{array}{l}\text { Protein } \\
\text { Marker }\end{array}$} & \multirow{2}{*}{$\begin{array}{l}\text { Antigen } \\
\text { Retrieval }\end{array}$} & \multirow{2}{*}{$\begin{array}{l}\text { Peroxidase } \\
\text { Inactivation }\end{array}$} & \multirow{2}{*}{$\begin{array}{l}\text { Detection } \\
\text { System }\end{array}$} & \multicolumn{3}{|c|}{ Antibody } \\
\hline & & & & Company & Dilution & $\begin{array}{c}\text { Incubation } \\
\text { Period }\end{array}$ \\
\hline VEGF-A & $\begin{array}{c}\text { EDTA Buffer } \\
1 X \\
\mathrm{pH}=8.0\end{array}$ & $\begin{array}{c}3 \% \mathrm{H}_{2} \mathrm{O}_{2} \text { in } \\
\text { methanol, } \\
10 \mathrm{~min}\end{array}$ & LabVision & Abcam & $1: 100$ & Overnight $4{ }^{\circ} \mathrm{C}$ \\
\hline VEGF-C & $\begin{array}{c}\text { EDTA Buffer } \\
1 X \\
\mathrm{pH}=8.0\end{array}$ & $\begin{array}{l}3 \% \mathrm{H}_{2} \mathrm{O}_{2} \text { in } \\
\text { methanol, } \\
10 \mathrm{~min}\end{array}$ & LabVision & Invitrogen & $1: 200$ & Overnight $4{ }^{\circ} \mathrm{C}$ \\
\hline VEGF-D & $\begin{array}{c}\text { EDTA Buffer } \\
1 X \\
\mathrm{pH}=8.0\end{array}$ & $\begin{array}{c}3 \% \mathrm{H}_{2} \mathrm{O}_{2} \text { in } \\
\text { methanol, } \\
10 \mathrm{~min}\end{array}$ & LabVision & Invitrogen & $1: 200$ & Overnight $4{ }^{\circ} \mathrm{C}$ \\
\hline VEGF-R2 & $\begin{array}{c}\text { Citrate } \\
\text { Buffer } 0.01 \mathrm{M} \\
\mathrm{pH}=6.0\end{array}$ & $\begin{array}{c}3 \% \mathrm{H}_{2} \mathrm{O}_{2} \text { in } \\
\text { methanol, } \\
10 \mathrm{~min}\end{array}$ & LabVision & Abcam & $1: 200$ & Overnight $4{ }^{\circ} \mathrm{C}$ \\
\hline VEGF-R3 & $\begin{array}{c}\text { Citrate } \\
\text { Buffer 0.01M } \\
\text { pH }=6.0\end{array}$ & $\begin{array}{c}3 \% \mathrm{H}_{2} \mathrm{O}_{2} \text { in } \\
\text { methanol, } \\
10 \mathrm{~min}\end{array}$ & LabVision & Abcam & $1: 100$ & Overnight $4{ }^{\circ} \mathrm{C}$ \\
\hline
\end{tabular}

Immunohistochemical Evaluation

Sections were scored semi-quantitatively for the extent and intensity of reactions: The extension of immunoreaction was scored as follows: $0: 0 \%$ of immunoreactive cells; $1:<5 \%$ of immunoreactive cells; 2 : $5-50 \%$ of immunoreactive cells; and 3: $>50 \%$ of immunoreactive cells. The intensity of staining was classified semi-qualitatively as 0: negative; 1 : weak; 2 : intermediate; and 3: strong. The final score for the immunoreaction was defined as the sum of both parameters (extent and intensity), and grouped as negative, 0; weak, 2; moderate, 3; and strong, 4-6 [32]. For statistical purposes, moderate and strong immunoreaction final scores were combined and considered as positive. Evaluation of VEGF immunohistochemical expression was performed blindly by two independent observers, project investigator and project co-supervisor, and discordant cases were discussed in order to determine a final score.

\subsection{Statistical Analysis}

All data were collected and stored in an Excel PC database (Microsoft ${ }^{\circledR}$ Office Excel 2013). Descriptive and inferential statistical analysis was performed using the Statistical Package for the Social Science (SPSS Inc., Chicago, IL, USA), version 25.0 for Windows ${ }^{\circledR}$.

All comparisons were examined for statistical significance using Pearson's chi-square $\left(\mathrm{X}^{2}\right)$ test and the Fisher's exact test (when $n<5$ ), with the threshold for significant p-values of less than 0.05 . Differences in expression between LNM and primary CRC were analyzed by the McNemar test, for $p<0.05$. Survival curves were determined for overall survival by the Kaplan-Meier method and the log-rank test.

\section{Conclusions}

The current study stablished new information that revealing the expression of the VEGF family and receptors is also increased in the lymph nodes metastasis. Also, the association between the expression of VEGFR-2and VEGFR-3 in lymph nodes with CRC relapse reveals its important negative impact on the worse prognosis of the patient.

Author Contributions: I.M., S.F.M., E.A.G., M.R., A.L. designed the structure of the study. S.F.M. and E.A.G. performed the CAIX immunohistochemical evaluation. S.F.M. and M.R. performed CRC surgery and are 
responsible for the CRC prospective database. S.F.M. and I.M. performed the statistical analysis. I.M. and S.F.M. wrote the final version of the manuscript. All authors read and approved the final manuscript.

Funding: This research received no external funding.

Conflicts of Interest: The authors declare no conflict of interest.

\section{References}

1. Des, G.D.; Uzzan, B.; Nicolas, P.; Cucherat, M.; Morere, J.F.; Benamouzig, R.; Breau, J.-L.; Perret, G.-Y. Microvessel density and VEGF expression are prognostic factors in colorectal cancer. Meta-analysis of the literature. Br. J. Cancer 2006, 19, 1823-1832.

2. Ferlay, J.; Shin, H.-R.; Bray, F.; Forman, D.; Mathers, C.; Parkin, D.M. Estimates of worldwide burden of cancer in 2008: GLOBOCAN 2008. Int. J. Cancer 2010, 127, 2893-2917. [CrossRef] [PubMed]

3. Van Cutsem, E.; Rodrigues, O. Colon cancer: ESMO Clinical Recommendations for diagnosis, adjuvant treatment and follow-up. Ann. Oncol. 2008, 19, ii29. [CrossRef] [PubMed]

4. Compton, C.C.; Fielding, L.P.; Burgart, L.J.; Conley, B.; Cooper, H.S.; Hamilton, S.R.; E Hammond, M.; Henson, D.E.; Hutter, R.V.; Nagle, R.B.; et al. Prognostic factors in colorectal cancer. College of American Pathologists Consensus Statement 1999. Arch. Pathol. Lab. Med. 2000, 124, 979-994. [PubMed]

5. Svagzdys, S.; Lesauskaite, V.; Pavalkis, D.; Nedzelskienè, I.; Pranys, D.; Tamelis, A. Microvessel density as new prognostic marker after radiotherapy in rectal cancer. BMC Cancer 2009, 9, 95. [CrossRef] [PubMed]

6. Martins, S.F.; Reis, R.M.; Rodrigues, A.M.; Baltazar, F.; Longatto, A. Role of endoglin and VEGF family expression in colorectal cancer prognosis and anti-angiogenic therapies. WJC 2011, 10, 272-280. [CrossRef] [PubMed]

7. Pang, P.W.; Rood, P. Clinical implications of angiogenesis in cancers. Vasc. Health Risk Manag. 2006, 2, 97-108. [CrossRef]

8. Myśliwiec, P.; Pawlak, K.; Kukliński, A.; Kedra, B. Combined perioperative plasma endoglin and VEGF-a assessment in colorectal cancer patients. Folia Histochem. Cytobiol. 2009, 47, 231-236. [CrossRef]

9. De Vita, F.; Orditura, M.; Lieto, E.; Infusino, S.; Morgillo, F.; Martinelli, E.; Castellano, P.; Romano, C.; Ciardiello, F.; Catalano, G.; et al. Elevated perioperative serum vascular endothelial growth factor levels in patients with colon carcinoma. Cancer 2004, 100, 270-278. [CrossRef]

10. Zheng, S.; Han, M.Y.; Xiao, Z.X.; Peng, J.P.; Dong, Q. Clinical significance of vascular endothelial growth factor expression and neovascularization in colorectal carcinoma. World J. Gastroenterol. 2003, 9, 1227-1230. [CrossRef]

11. Kannarkatt, J.; Joseph, J.; Kurniali, P.C.; Al-Janadi, A.; Hrinczenko, B. Adjuvant chemotherapy for stage II colon cancer: A clinical dilemma. J. Oncol. Pract. 2017, 13, 233-241. [CrossRef]

12. Hanrahan, V.; Currie, M.J.; Gunningham, S.P.; Morrin, H.R.; Scott, P.A.; Robinson, B.; Fox, S.B. The angiogenic switch for vascular endothelial growth factor (VEGF)-A, VEGF-B, VEGF-C, and VEGF-D in the adenoma-carcinoma sequence during colorectal cancer progression. J. Pathol. 2003, 100, 183-194. [CrossRef] [PubMed]

13. Martins, S.F.; García, E.A.; Luz, M.A.M.; Pardal, F.; Rodrigues, M.; Filho, A.L.L. Clinicopathological correlation and prognostic significance of VEGF-A, VEGF-C, VEGFR-2 and VEGFR-3 expression in colorectal cancer. Cancer Genom. Proteom. 2013, 10, 55-67.

14. Liang, J.-F.; Wang, H.-K.; Xiao, H.; Li, N.; Cheng, C.-X.; Zhao, Y.-Z.; Ma, Y.-B.; Gao, J.-Z.; Bai, R.-B.; Zheng, H.-X. Relationship and prognostic significance of SPARC and VEGF protein expression in colon cancer. J. Exp. Clin. Cancer Res. 2010, 29, 71. [CrossRef] [PubMed]

15. Gurzu, S.; Jung, J.; Azamfirei, L.; Mezei, T.; Cîmpean, A.M.; Szentirmay, Z. The angiogenesis in colorectal carcinomas with and without lymph node metastases. Rom. J. Morphol. Embryol. 2008, 49, 149-152. [PubMed]

16. Rodrigo, J.P.; Cabanillas, R.; Chiara, M.D.; Pedrero, J.G.; Astudillo, A.; Nieto, C.S. Prognostic significance of angiogenesis in surgically treated supraglottic squamous cell carcinomas of the larynx. Acta Otorrinolaringol. Esp. 2009, 60, 272-277. [CrossRef]

17. Cascinu, S.; Staccioli, M.P.; Gasparini, G.; Giordani, P.; Catalano, V.; Ghiselli, R.; Rossi, C.; Baldelli, A.M.; Graziano, F.; Saba, V.; et al. Expression of vascular endothelial growth factor can predict event-free survival in stage II colon cancer. Clin. Cancer Res. 2000, 6, 2803-2807. [PubMed] 
18. Saad, R.S.; Liu, Y.L.; Nathan, G.; Celebrezze, J.; Celebrezze, J.; Silverman, J.F. Endoglin (CD105) and vascular endothelial growth factor as prognostic markers in colorectal cancer. Mod. Pathol. 2004, 17, 197-203. [CrossRef]

19. Secker, G.A.; Harvey, N.H. VEGFR signaling during lymphatic vascular development: From progenitor cells to functional vessels. Dev. Dyn. 2015, 244, 323-331. [CrossRef]

20. Miettinen, M.; Rikala, M.-S.; Rys, J.; Lasota, J.; Wang, Z.-F.; Rysz, J. Vascular endothelial growth factor receptor 2 as a marker for malignant vascular tumors and mesothelioma: An immunohistochemical study of 262 vascular endothelial and 1640 nonvascular tumors. Am. J. Surg. Pathol. 2012, 36, 629-639. [CrossRef]

21. Rivard, A.; Berthou-Soulie, L.; Principe, N.; Kearney, M.; Curry, C.; Branellec, D.; Semenza, G.L.; Isner, J.M. Age-dependent defect in vascular endothelial growth factor expression is associated with reduced hypoxia-inducible factor 1 activity. J. Biol. Chem. 2000, 275, 29643-29647. [CrossRef] [PubMed]

22. Ito, Y.; Betsuyaku, T.; Nagai, K.; Nasuhara, Y.; Nishimura, M. Expression of pulmonary VEGF family declines with age and is further down-regulated in lipopolysaccharide (LPS)-induced lung injury. Exp. Gerontol. 2005, 40, 315-323. [CrossRef] [PubMed]

23. Pola, R.; Aprahamian, T.; Bosch-Marce, M.; Curry, C.; Gaetani, E.; Flex, A.; Smith, R.C.; Isner, J.M.; Losordo, U.W. Age-dependent VEGF expression and intraneural neovascularization during regeneration of peripheral nerves. Neurobiol. Aging 2004, 25, 1361-1368. [CrossRef] [PubMed]

24. Talagas, M.; Uguen, A.; Garlantezec, R.; Fournier, G.; Doucet, L.; Gobin, E.; Marcorelles, P.; Volant, A.; De Braekeleer, M. VEGFR1 and NRP1 endothelial expressions predict distant relapse after radical prostatectomy in clinically localized prostate cancer. Anticancer Res. 2013, 33, 2065-2075.

25. Bolander, A.; Wagenius, G.; Larsson, A.; Brattström, D.; Ullenhag, G.; Hesselius, P.; Ekman, S.; Bergqvist, M. The role of circulating angiogenic factors in patients operated on for localized malignant melanoma. Anticancer. Res. 2007, 27, 3211-3217.

26. Berardi, R.; Torniai, M.; Partelli, S.; Rubini, C.; Pagliaretta, S.; Savini, A.; Polenta, V.; Santoni, M.; Giampieri, R.; Onorati, S.; et al. Impact of vascular endothelial growth factor (VEGF) and vascular endothelial growth factor receptor (VEGFR) single nucleotide polymorphisms on outcome in gastroenteropancreatic neuroendocrine neoplasms. PLoS ONE 2018, 13, e0197035. [CrossRef]

27. Saharinen, P.; Tammela, T.; Karkkainen, M.J.; Alitalo, K. Lymphatic vasculature: Development, molecular regulation and role in tumor metastasis and inflammation. Trends Immunol. 2004, 25, 387-395. [CrossRef]

28. Folpe, A.L.; Veikkola, T.; Valtola, R.; Weiss, S.W. Vascular endothelial growth factor receptor-3 (VEGFR-3): A marker of vascular tumors with presumed lymphatic differentiation, including Kaposi's sarcoma, kaposiform and Dabska-type hemangioendotheliomas, and a subset of angiosarcomas. Mod. Pathol. 2000, 13, 180-185. [CrossRef]

29. Alessi, C.; Neto, C.S.; Viana, C.R.; Vazquez, V.D.L. PD-1/PD-L1 and VEGF-A/VEGF-C expression in lymph node microenvironment and association with melanoma metastasis and survival. Melanoma Res. 2017, 27, 565-572. [CrossRef]

30. Chen, Y.; Liu, Y.; Wang, Y.; Li, W.; Wang, X.; Liu, X.; Chen, Y.; Ouyang, C.; Wang, J. Quantification of STAT3 and VEGF expression for molecular diagnosis of lymph node metastasis in breast cancer. Medicine (Baltimore) 2017, 96, e8488. [CrossRef]

31. Greene, F.; Page, D.; Fleming, I.; Fritz, A.; Balch, C. AJCC Cancer Staging Manual, 7th ed.; Springer: New York, NY, USA, 2002.

32. Pinheiro, C.; Longatto-Filho, A.; Cristovam, S.; Ferreira, L.; Martins, S.; Pellerin, L.; Rodrigues, M.; Alves, A.F.V.; Schimtt, F.; Baltazar, F. Increased expression of monocarboxylate transporters 1, 2, and 4 in colorectal carcinomas. Virchows Arch. 2008, 452, 139-146. [CrossRef] [PubMed]

(C) 2020 by the authors. Licensee MDPI, Basel, Switzerland. This article is an open access article distributed under the terms and conditions of the Creative Commons Attribution (CC BY) license (http://creativecommons.org/licenses/by/4.0/). 